\section{Heed local impact of coal mining}

It is alarming that US President Donald Trump has halted research on the health and environmental risks of coal mining (Nature 548, 499; 2017). Investigating and documenting the harmful effects of coal extraction on miners and local populations is essential - and the results would bolster support for decarbonization of the energy sector (see also C. Figueres et al. Nature 546, 593-595; 2017).

Scientists, donor agencies and policymakers must all turn their attention to marginalized groups in coal-mining regions. In Indonesia, for example, the rapid expansion of coal mining has affected health and livelihoods, and polluted water and air (B. Brown and S. J. Spiegel Geoforum 85, 101-111; 2017). Furthermore, these injustices are fuelling climate change.

Even though energy policies are entangled in complex webs of political and economic power, scientists and activists have successfully pushed for commitments to phase out coalfired power in some countries (notably in the United Kingdom by 2025 , in France by 2022 and in Canada by 2030). This stands in contrast to the United States, where increased demand from Europe and Asia has boosted coal exports by $60 \%$ since last year (see go.nature.com/2y7qyut), despite a decline in exports during 2012-16.

Samuel Spiegel, Benjamin Brown University of Edinburgh, UK. sspiegel@exseed.ed.ac.uk

\section{Hurricanes: rescue natural defences}

Decades of land development in the eastern United States and the Caribbean have increased the impact of the 2017 hurricanes Harvey, Irma and Maria. Because such events are likely to intensify as a result of climate change, societies must bolster natural defences and cease contributing to their own vulnerability.

We know from many examples worldwide that dense urbanization of low-lying coastal areas makes them more prone to the impacts of flooding, especially where buffering ecosystems have been squeezed. Take Saint Martin, the Caribbean island that was one of the most severely hit by Hurricane Irma in September. Since 1986, it has been subject to uncontrolled urbanization of its barrier beaches. A category- 4 tropical cyclone known as Luis wiped out settlements there in 1995, but the public authorities did not prevent developers and residents from rebuilding them. This explains the extent of the damage by Irma.

We urgently need to reverse and stop large-scale developments that prevent buffering by natural ecosystems. Only then can we counter the threat of natural hazards and stimulate adaptation pathways to climate change.

Virginie K. E. Duvat University of La Rochelle and CNRS, La Rochelle, France.

Alexandre K. Magnan IDDRI, Paris, France.

alexandre.magnan@iddri.org

\section{Hurricanes: enlist nature's protection}

Hurricanes Harvey, Irma and Maria, which hit in August and September, are estimated to be the most costly ever to make landfall in the United States. The damage they caused calls for a major investment in infrastructure that is resilient to such extreme events. Underpinning this infrastructure with nature-based solutions is no longer enough - these need to be promoted to centre stage.

Street trees, parks and green roofs in cities, along with nearby meadows, forests and wetlands, absorb storm water and can attenuate storm surges, mitigating the worst impacts of flooding and so saving lives and money. We must shift how we plan and build our cities so that we create and protect such ecosystems.

The United States also needs a major federal plan to invest in flexible, adaptive and safe-to-fail infrastructure to protect cities, particularly on the coast - for example, by restoring wetlands and coral and oyster reefs along the US eastern seaboard. The Indian Bend Wash Greenbelt, a complex of parks and lakes in Scottsdale, Arizona, is a successful example: it was designed to be floodable to spare the city (see go.nature.com/2fz2hjt).

President Trump promised investment in infrastructure to drive economic growth and create jobs. Green infrastructure should be an essential part of the deal.

Timon McPhearson Cary Institute of Ecosystem Studies, Millbrook, New York.

timon.mcphearson@newschool.edu

\section{UNESCO honour for Polish mining facility}

The United Nations Educational, Scientific and Cultural Organization (UNESCO) has added a third Polish geological site to its World Heritage List. It is the Tarnowskie Góry Lead-Silver-Zinc Mine and its Underground Water Management System (go.nature. com/2xez7jy; see also go. nature.com/2ytbhny and go.nature.com/2hyzhii).

Metallic ores have been extracted from the site since the twelfth century. A galena lead ore deposit discovered there in 1526 was mined until it ran out in 1912. The mine was abandoned in the 1930s, and a museum and underground tourist route were eventually opened there in 1976 (V. Coppola et al. Miner. Deposita 44, 559-580; 2009).

The vast labyrinths under Tarnowskie Góry also house a water station and more than 150 kilometres of drainage galleries. This ingenious gravitybased water-management system conserved the excess water from the mine for public use. It still operates today, largely in the way it was designed more than two centuries ago. The mine now forms one of Poland's largest overwintering areas for bats.

To be included on the World Heritage List, sites must be of exceptional universal value. The Tarnowskie Góry site qualifies because it is "a masterpiece of human creative genius" and "an outstanding example of a technological ensemble that contributed to significant stages in human history".

Ryszard Chybiorz, Bogumiła A. Piwowar University of Silesia in Katowice, Katowice, Poland. bogumila.piwowar@us.edu.pl

\section{Blockchain could boost food security}

Blockchain technology is helping to meet sustainability challenges (see G. Chapron Nature 545, 403-405; 2017), for example in renewable energy $(\mathrm{M}$. Andoni et al. Nature 548,$158 ; 2017)$ and conservation (Z. Baynham-Herd Nature 548, 523; 2017). Food security could also benefit from the technology's transparency, relatively low transaction costs and instantaneous application.

Blockchain assignment of unique digital identifiers to food products would make them traceable through supply chains, along with their growth conditions, batch numbers and expiry dates. This would help to prevent food waste, allow consumers to work out the ecological footprint of their food, and guide the distribution of surplus food to those who need it.

This shared and immutable register of foods and transactions would prevent fraud and enable source identification of foodborne illness. And as digital technologies are increasingly used to manage farms, blockchain will promote sharing of on-farm data. Selena Ahmed, Noah ten Broek Montana State University, Bozeman, Montana, USA. selena.ahmed@montana.edu 